\title{
Land transformation assessment using the integration of remote sensing and GIS techniques: a case study of Al-Anbar Province, Iraq
}

\begin{abstract}
Human activities and climate changes significantly affect our environment, altering hydrologic cycles. Several environmental, social, political, and economical factors contribute to land transformation as well as environmental changes. This study first identified the most critical factors that affect the environment in Al-Anbar city including population growth, urbanization expansion, bare land expansion, and reduction in vegetation cover. The combination of remote sensing data and fuzzy analytic hierarch process (Fuzzy AHP) enabled exploration of land transformations and environmental changes in the study area during 2001 to 2013 in terms of long and short-term changes. Results of land transformation showed that the major changes in water bodies increased radically (94\%) from the long-term change in 2001 to 2013 because of water policies. In addition, the urban class expanded in two shortterm periods (2001-2007 and 2007-2013), representing net changes of 46 and $60 \%$, respectively. Finally, barren land showed $25 \%$ reduction in the first period because of the huge expansion of water in the lake; a small percentage of growth gain was observed in the second period. Based on the land transformation results, the environmental degradation assessment showed that the study area generally had high level of environmental degradation. The degradation was mostly in the center and the north part of the study area. This study suggested for further studies to include other factors that also responsible for environmental degradation such as water quality and desertification threatening.
\end{abstract}

Keyword: GIS modeling; Fuzzy AHP; Land transformation; Environmental degradation; EDI 